\title{
Insulin Resistance and Beta Cell Dysfunction in Severe Falciparum Malaria with Multi Organ Dysfunction Syndrome (MODS)
}

\author{
Manoj Kumar Mohapatra ${ }^{1}$, MuralidharAnantrao Sangle ${ }^{2}$, Prafulla Kumar Bariha ${ }^{3}$ \\ ${ }^{1}$ Professor, Dept. of General Medicine \\ ${ }^{2}$ Postgraduate, Department of General Medicine \\ ${ }^{3}$ Asst. Prof., Department of General Medicine \\ VSS Institute of Medical Sciences and Research, Burla, Sambalpur, Odisha
}

Abstract:-

\section{Background}

Insulin Resistance is a major factor among patients with critical illness due to various causes. Severe falciparum malaria with MODS diagnosed as per the criteria of MSS and admitted to the Medical ward of our hospital were assessed for IR and $\beta$ cell function by using homeostasis model assessment.

\section{Material Methods}

75 consecutive patients of SFM admitted to the Medical ward of our hospital were included in this study. Malaria was diagnosed as per criteria of WHO and organ dysfunction was diagnosed as per Malaria Severity Score. Insulin Resistance and $\beta$ cell function was assessed by using homeostasis model assessment on Day-1 and Day-7.

\section{$>$ Results}

Out of 75 patients of severe falciparum malaria with MODS 2, 3, 4, and 5 organ dysfunctions constituted $16(21.3 \%), 34(45.3 \%), 16(21.3 \%)$, and $9(12.0 \%)$ patients, respectively.Hepatic failure was the most common organ system failure $(n=58 ; 77.3 \%)$, followed by neurological $(n=50 ; 66.6 \%)$,renal $(n=40 ; 53.3 \%)$, hematological $(n=30 ; 40.0 \%)$, and, respiratory failure ( $\mathrm{n}=15 ; 20.0 \%)$. Hyperglycemia was present in $25(33.3 \%)$ cases where as normoglycemia was present in $50(66.6 \%)$ cases. The values of FBS, Tg, insulin, IR, and $\beta$ cell function decreased on Day-7 compared to Day-1 after recovery from critically ill state. The patients who died had a high insulin value, IR, but low $\beta$ cell dysfunction compared to the survivors.

\section{Conclusion}

This study showed that IR and $\beta$ cell dysfunction were associated with severe malaria with MODS with increased mortality.

\section{INTRODUCTION}

Insulin resistance (IR) is a metabolic state in which anabolic processes are not responsive to normal effects of insulin in the presence of normal or elevated plasma insulin concentration. As a result, a diabetic like state due to hyperglycemia, negative nitrogen balance, muscle wasting, increased lipid metabolism causing raised triglyceride and free fatty acid, anaerobic glycolysis causing lactic acidosis are found ${ }^{1}$. It is usually associated with critical illnesses including sepsisand affect the outcome adversely ${ }^{2}$.

Like sepsis severe falciparum malaria (SM)is characterized by a series of clinical, hematological, and metabolic responses leading to multi organ dysfunction syndrome (MODS) and the mortality increased with increasing number of organ dysfunctions ${ }^{3}$. It has been found that stress hyperglycemia due to IR and $\beta$-cell dysfunction was found among patients with sepsis and MODS affecting the outcome adversely. Therefore, the present study was undertaken to study IR and $\beta$ - cell dysfunction among patients with SM with MODS and its role in mortality.

\section{MATERIAL METHODS}

The present study was undertaken at Dept. of Medicine of VSS Institute of Medical Sciences and Research, Burla, Sambalpur, Odisha, India from 2016-18.

Patients of severe falciparum malaria with MODS were included in this study. The diagnosis of falciparum malaria was made with detection of asexual form of the parasite in the Giemsa stained peripheral blood smear and / or rapid diagnostic test (RDT). The diagnosis of MODS was made according to the definition of organ dysfunction and assessment of severity by Malaria Severity Score (MSS) that is developed in our center ${ }^{4}$.

The diagnosis of severe malaria was made according to the WHO criteria 5 . 
Patients with Diabetes mellitus, pancreatitis, corticosteroid therapy, cirrhosis of liver, chronic renal failure were excluded from the study. In patients with newly detected hyperglycemia, an elevated $\mathrm{HbA1C}$ value, above $7 \%$, suggests the presence of DM, hence excluded from the study.

75 consecutive patients of severe falciparum malaria with MODS in the age group of 15 to 70 years were enrolled in this study. There was a male predominance in this study group with the ratio $\mathrm{M}: \mathrm{F}=4: 1$, and majority of males were in the 21 to 40 years of age group; most of the females were in 41 to 50 years of age group. Detailed history, physical examination, hematological investigations, liver function tests, renal function tests, serum sodium, potassium, serum triglyceride (Tg), fasting blood sugar (FBS), serum insulin, and glycosylated hemoglobin were evaluated in each case at the point of entry. When we could not collect the blood at the time of admission, it was collected next day at 8 A.M.Care had been taken not to administer intravenous dextrose solution and lipid before collection of blood sample. All the patients were treated with Inj. Artesunate and other organ support treatment as per the WHO guidelines ${ }^{6}$.

The blood was collected after 7 days for comparison of results. Most of the patients $(n=35)$ recovered by 7 days. For uniformity of comparison, even if the hospital stay was more in 15 cases, we have taken investigation data of $7^{\text {th }}$ day. Stress hyperglycemia is defined as blood glucose > $110 \mathrm{mg} / \mathrm{dl}$.Insulin resistance (IR) and $\beta$ cell function was calculated from HOMA model. HOMA-R $=$ Insulin $\times$ Fasting blood Glucose (FBG) /405. $\beta$ cell function(HOMA$B)$ in percentage was calculated from Homeostatic model assessment (HOMA) ${ }^{7}$.

Statistical analysis was done by SPSS version11. Mean and SD were calculated. Students t test was used for comparison between values of two groups.

\section{RESULTS}

The present study enrolled 75 patients of severe falciparum malaria and all were followed up on 7 days. There was a male preponderance in the study (6:1), and they were in the 20-35 years of age group; females were in 40 to 50 years of age. Hepatic failure was the most common organ system failure $(\mathrm{n}=58 ; 77.3 \%)$, followed by neurological $(\mathrm{n}=50 ; 66.6 \%)$,renal $(\mathrm{n}=40 ; 53.3 \%)$, hematological $(\mathrm{n}=30$; $40.0 \%)$, and, respiratory failure $(n=15 ; 20.0 \%)$. Two, 3, 4, and 5 organ dysfunctions constituted 16 (21.3\%), 34 (45.3\%), 16 (21.3\%), and 9 (12.0\%)patients, respectively.Cerebral malaria, hepatic, and renal involvement was the most common combination of organ dysfunctions found in this study 4 (45.3\%).

Table-I shows the comparison of IR and B cell function on admission and after 7 days. The mean glycosylated hemoglobin of these patients was 5.6 \pm 2.7 . The values of FBS, Tg, insulin, IR, and $\beta$ cell function decreased on Day-7 compared to Day-1 after recovery from critically ill state.

Hyperglycemia was present in $25(33.3 \%)$ cases where as normoglycemia was present in $50(66.6 \%)$ cases. There was significant higher insulin and IR among the patients with stress hyperglycemia than normoglycemia (Table-2). Most hyperglycemic patients had 4 or more OD $(n=15$, $60.0 \%)$. Most of them died $(n=10,66.6 \%)$ and rest 5 $(33.3 \%)$ did not recover during the study period of 7 days. These patients had high Tg, FBS, IR, $\beta$ cell function as compared to normoglycemic patients.

Fifteen cases $(25.0 \%)$ died during the study. Out of them $1(6.2 \%), 4(11.7 \%), 5(31.2 \%)$, and $5(55.5 \%)$ belonged to $2,3,4$, and 5 organ dysfunctions, respectively. Thus, 5 non-survivors $(33.3 \%)$ belonged to 3 whereas rest $10(66.6 \%)$ had 4 or more organ dysfunctions. The patients who died had a high insulin value, IR, but low $\beta$ cell dysfunction compared to the survivors (Table-3).

Table-4 shows levels of IR and $\beta$-cell function with $\leq$ 3 and $\geq 4$ organ failure. In patients with $<4$ OF $(n=50)$ have significant low levels of $\mathrm{Tg}$, insulin, IR during recovery, whereas these values remained high during recovery in patients with $>4$ organ failure.

\section{DISCUSSION}

The present study showed thathyperinsulinemic hyperglycemia due to IR and $\beta$-cell dysfunction was found in about $1 / 3^{\text {rd }}$ of patients with SM. It has been associated with high mortality affecting the outcome adversely.

Hyperglycemia associated with IR was comparable with other studies related to sepsis ${ }^{2,8}$. However, patients with cerebral malaria had IR and $\beta$-cell dysfunction causing hyperinsulinemic hyperglycemia ${ }^{9}$.

The causes of IR are multiple. IR is mostly due to the combined effect of the neuroendocrine and cytokine systems. Hyperglycemic group in our studies have more IR and poorer $\beta$ cell function. It appears that upsurge in cytokines and other immunomodulators adversely affect $\beta$ cell function, leading to hyperglycemia with concomitant relative insulin deficiency as observed in our patients. MODS patients are insulin deficient because of $\beta$ cell failure ${ }^{10}$.Stress hyperglycemia stimulates the otherwise healthy $\beta$ cells of the pancreas to produce an excess insulin, and thus hyperinsulinemia occurs. IR is a good and easily estimated method for assessing the severity of morbidity in MODS with 3 organ dysfunctions. Constant stimulation leads to over exhaustion of $\beta$ cells leading to $\beta$ cell failure among patients with dysfunction of 4 organs.

Apart from hyperglycemia, IR is associated with lipid abnormalities with increased free fatty acids and $\mathrm{Tg}^{2}$. In the present study, hypertriglyceridemia is the main feature of altered fat metabolism which is similar to studies in critically ill patients. We found that stress induced IR reduced after reduction of stress with treatment after 7 days. 
The glucose homeostasis in SM is complex. Hypoglycemia has been considered as an isolated complication of SM which has been attributed to consumption of glucose by the parasites mostly virulent strains, use of quinine as the drug of $1^{\text {st }}$ choice, less intake, and hyperinsulinemia ${ }^{11,12}$.

In experimental malaria increased plasma insulin and hypoglycemia was also observed ${ }^{13}$. However, association of hyperglycemia in SM is not uncommon and has been reported by different authors and high mortality rate of $\mathrm{CM}$ among children had been associated with hyperglycemia ${ }^{14}$.In adults also the mortality among SM with MODS has been associated with hyperglycemia with $\mathrm{IR}^{2}$.

In falciparum malaria both hypoglycemia and hyperglycemia are observed depending on the clinical conditions ${ }^{11,14}$. Hypoglycemia was a metabolic complication which was more common when quinine has been administered as treatment ${ }^{12}$.Now with the use of artesunate the incidence of hypoglycemia has been detected less frequently ${ }^{4}$. Hyperglycemia was found among patients with cerebral malaria 9 .

Insulin secretion is stimulated by plasma glucose and potentially inhibited by pancreatic $\beta$ cell function. Increased insulin with normal glucose indicated IR, while increased glucose with increased insulin indicates IR with $\beta$ cell function $^{2,8,9}$. Here, hyperglycemia with hyperinsulinemia were indicative of IR with $\beta$ cell dysfunction. Physiologically, normal $\beta$ cell function can overcome the stress hyperglycemia but over exhaustion cause dysfunction aggravating the state of $\mathrm{IR}^{1}$.

Severe falciparum malaria with MODS is associated with high mortality that increased with number of organ dysfunction $^{3,15}$. Hyperglycemia is potentially harmful causing increased risk of death due to its procoagulant effect, impaired neutrophil function, increased apoptosis. Hyperinsulinemias hyperglycemia is also associated with severe malaria with MODS with increased mortalityindicating bad prognosis.

\section{REFERENCES}

[1]. Carlson GL. Insulin resistance in human sepsis: implications for the nutritional and metabolic care of the critically ill surgical patient. Ann R Coll Surg Engl, 2004;86:75-81.

[2]. Das S, Misra B, Roul L, Minz NT, Pattnaik M, Baig MAA. Insulin resistance and $\beta$-cell function as prognostic indicator in Multi-organ dysfunction syndrome. Met Syn Rel Dis, 2009;7:47-51.

[3]. Mohapatra MK. The natural history of complicated falciparum malaria- A prospective study. J Asso Phys Ind, 2006;54: 848-53.
[4]. Mohapatra MK, Das SP. The Malaria Severity Score: a method for severity assessment and risk prediction of hospital mortality for falciparum malaria in adults. $J$ Asso Phys Ind, 2009; 57: 119-126.

[5]. World Health Organization, Communicable Diseases Cluster: Severe falciparum malaria. Trans Roy Soc Trop Med Hyg 2000, 94(Suppl 1):S1-90.

[6]. Guidelines for the treatment of Malaria, $3^{\text {rd }}$ Edition. World HealthOrganization, 2015; $3^{\text {rd }}$ edition: 1-62. www.who.int.

[7]. Matthews DR, Hoskar JP, Rudenski AS, Naylor BA, Treacher DF, Turner RC. Homeostasis model assessment: insulin resistance and $\beta$-cell function from fasting plasma glucose and insulin concentration in man. Diabetologia, 1985;28:412-419.

[8]. Gheorghita v, Barbu AE, Gheorghiu ML, Caruntu FA. Endocrine dysfunction in sepsis: a beneficial or deleterious host response? Germs, 2015; 5:17-25. Doi:10.11599/germs.2015.1067.

[9]. Eltahir EM, ElGhazali G, A-Elgadir TME, A-Elbasit IE, Elbashir MI, Giha HA. Raised plasma insulin level and homeostasis model assessment (HOMA) score in cerebral malaria; evidence for insulin resistance and marker of virulence. Acta Biochimica Polonica, 2010; 57:513-520.

[10]. Anderson SK, Gjedsted J, Christiansen C, Tonnessen E. The roles of insulin and hyperglycemia in sepsis pathogenesis. J Leukoc Biol, 2004;75:413-421.

[11]. White NJ, Warrel DA, Chanthavanich P, Looareesuwan S, Warrel MJ, Krishna S, Williamson DH, Turner RC. Severe hypoglycemia and hyperinsulinemia in falciparum malaria. $N$ Eng $\mathrm{J} \mathrm{Med}$, 1983;309(2):61-66.

[12]. Elbadawi NEE, Mohamed MI, Dawod OY, Ali KE, Daoud OH, Ali EM, Ahmed EGE, Mohamed AE. Effect of quinine therapy on plasma glucose and plasma insulin levels in pregnant women infected with Plasmodium falciparum malaria in Gezira state. East Medite Health J, 2011; 17: 697-700.)

[13]. Elased K, Playfair JH. Hypoglycemia and hyperinsulinemia in rodent models of severe malaria infection. Infect Immun, 1994;62:5157-60.)

[14]. Osier FH, Berkley JA, Ross A, Sanderson F, Mohammed S, Newton CR. Abnormal blood glucose concentrations on admission to a rural Kenyan district hospital:prevalence and outcome. Arch Dis Child, 2003;88:621-25.

[15]. Planche T, Dzeing A, Ngou-Milama E, Kombila M, Stacpoole PW. Metabolic complications of severe malaria. Curr Top Microbiol Immunol, 2005;295:105136. 
ISSN No:-2456-2165

\begin{tabular}{|c|c|c|c|}
\hline Variables & Day-1 & Day-7 & Probability \\
\hline Tg $(\mathrm{mg} / \mathrm{dl})$ & $260.9 \pm 99.8$ & $189.9 \pm 102.7$ & 0.001 \\
\hline FBS $(\mathrm{mg} / \mathrm{dl})$ & $124.7 \pm 39.5$ & $110.8 \pm 29.4$ & $0.1(\mathrm{NS})$ \\
\hline Insulin $(\mathrm{mU} / \mathrm{mL})$ & $17.8 \pm 4.5$ & $12.3 \pm 9.2$ & 0.001 \\
\hline IR & $7.3 \pm 9.5$ & $2.7 \pm 4.9$ & 0.01 \\
\hline$\beta$ cell function (\%) & $221.6 \pm 139.5$ & $210.8 \pm 239.7$ & $0.5(\mathrm{NS})$ \\
\hline
\end{tabular}

Table-1. Comparison of IR and B cell function of patients on Day $1 \& 7(n=75)$

\begin{tabular}{|c|c|c|c|}
\hline Variables & Hyperglycemia $(\mathbf{n = 2 5})$ & Normoglycemia $(\mathbf{n}=50)$ & Probability \\
\hline Tg $(\mathrm{mg} / \mathrm{dl})$ & $270.9 \pm 109.8$ & $199.8 \pm 104.5$ & $0.01 \mathrm{NS}$ \\
\hline FBS (mg/dl) & $164.3 \pm 27.5$ & $90.8 \pm 29.4$ & 0.01 \\
\hline Insulin (mU/mL) & $22.8 \pm 5.3$ & $14.3 \pm 9.5$ & 0.001 \\
\hline IR & $9.9 \pm 11.5$ & $2.5 \pm 3.9$ & 0.01 \\
\hline Bcell function (\%) & $88.7 \pm 68.5$ & $270.8 \pm 439.7$ & 0.05 \\
\hline
\end{tabular}

Table-2. Comparison of IR and B cell function of patients with Stress Hyperglycemia with Normoglycemia on Day of admission

\begin{tabular}{|c|c|c|c|}
\hline Variables & Survivors $(\mathbf{n = 6 0})$ & Death $(\mathbf{n}=15)$ & Probability \\
\hline Tg $(\mathrm{mg} / \mathrm{dl})$ & $257.7 \pm 88.8$ & $240.9 \pm 102.7$ & $0.1 \mathrm{NS}$ \\
\hline FBS $(\mathrm{mg} / \mathrm{dl})$ & $122.7 \pm 34.5$ & $156.5 \pm 29.4$ & $0.1(\mathrm{NS})$ \\
\hline Insulin $(\mathrm{mU} / \mathrm{mL})$ & $16.4 \pm 10.5$ & $13.3 \pm 9.2$ & $0.1 \mathrm{NS}$ \\
\hline IR & $7.8 \pm 9.5$ & $5.9 \pm 7.9$ & 0.01 \\
\hline$\beta$ cell function (\%) & $227.6 \pm 139.5$ & $49.8 \pm 239.7$ & 0.005 \\
\hline
\end{tabular}

Table-3. Comparison of IR and B cell function of patients with survivors and Death

\begin{tabular}{|c|c|c|c|c|c|c|}
\hline Variables & $\begin{array}{c}\leq 3 \text { organ failure } \\
(\mathrm{n}=50) \\
\text { Day-1 }\end{array}$ & $\begin{array}{c}\leq 3 \text { organ } \\
\text { failure } \\
\text { Day }-7\end{array}$ & $\mathbf{p}$ & $\begin{array}{c}\geq 4 \text { organ failure } \\
(n=25) \\
\text { Day-1 }\end{array}$ & $\begin{array}{c}\geq 4 \text { organ failure } \\
\text { Day-7 }\end{array}$ & $\mathbf{P}$ \\
\hline $\mathrm{Tg}(\mathrm{mg} / \mathrm{dl})$ & $275.4 \pm 68.6$ & $197.7 \pm 56.4$ & & $286.7 \pm 77.8$ & $244.7 \pm 102.7$ & $0.1 \mathrm{NS}$ \\
\hline FBS (mg/dl) & $142.6 \pm 24.5$ & $121.6 \pm 34.5$ & & $134.3 \pm 22.4$ & $126.4 \pm 29.4$ & $0.1(\mathrm{NS})$ \\
\hline Insulin $(\mathrm{mU} / \mathrm{mL})$ & $18.2 \pm 9.5$ & $12.2 \pm 6.3$ & & $19.1 \pm 8.5$ & $11.3 \pm 6.2$ & $0.1 \mathrm{NS}$ \\
\hline IR & $8.4 \pm 4.4$ & $6.8 \pm 3.6$ & & $9.8 \pm 7.4$ & $5.4 \pm 6.6$ & 0.01 \\
\hline $\begin{array}{c}\beta \text { cell function } \\
(\%)\end{array}$ & $217.5 \pm 129.5$ & $207.4 \pm 113.3$ & & $232.4 \pm 117.5$ & $58.8 \pm 109.7$ & 0.005 \\
\hline
\end{tabular}

Table-4. Comparison of IR and B cell function of patients with $\leq 3$ organ and $\geq 4$ organ failure 